Портовенозная эмболизашия в хирургии

3Аокачественных новообразований печени

DOI: 10.16931/1995-5464.2016334-46

Применение КТ-волюметрии и кАиренс-теста с иньошианином зеленым Аля определения показаний к преАоперашионной эмболизашии воротной вены

\author{
Дзидзава И.И. ${ }^{1}$, Слободяник А.В. ${ }^{1}$, Кудрявцева А.В. ${ }^{3}$, Железняк И.С. ${ }^{3}$, \\ Котив Б.Н.. ${ }^{1,}$, Алентьев С.А. ${ }^{2}$, Лазуткин М.B. ${ }^{2}$, Солдатов С.A. ${ }^{1}$ \\ ${ }^{1}$ Кафедра госпитальной хирургии, ${ }^{2}$ кафедра общей хирургии, ${ }^{3}$ кафедра рентгенологии и радиологии \\ с курсом ультразвуковой диагностики, ФГБВОУ ВО “Военно-медицинская академия им. С.М. Кирова” \\ Министерства обороны Российской Федерации; 194044, г. Санкт-Петербург, ул. Академика Лебедева, \\ д. 6, Российская Федерация
}

\begin{abstract}
Цель. На основании результатов КТ-волюметрии и клиренса индоцианина зеленого как факторов прогноза пострезекционной печеночной недостаточности уточнить показания к предоперационной эмболизации воротной вены.

Материал и методы. Анализировали результаты 179 резекций печени: 128 различных гемигепатэктомий и 51 секционэктомии. В 24 наблюдениях применяли предоперационную эмболизацию воротной вены. Для количественной оценки функции печени выполняли клиренс-тест с индоцианином зеленым. Определяли скорость плазменной элиминации и остаточную концентрацию на 15-й минуте. Для расчета планируемого пострезекционного объема печени использовали КТ-волюметрию. Степень тяжести пострезекционной печеночной недостаточности оценивали в соответствии с рекомендациями Международной исследовательской группы по хирургии печени (ISGLS) и с учетом критериев “50-50”.

Результаты. Частота пострезекционной печеночной недостаточности при обширных резекциях составила 42,5\%: степень A - 38,7\%; степень В - 41,9\%, степень С - 19,4\%. Планируемый пострезекционный объем как
\end{abstract}

\begin{abstract}
Дзидзава Илья Игоревич - доктор мед. наук, доцент, начальник кафедры (клиники) госпитальной хирургии, ФГБВОУ ВО “Военно-медицинская академия им. С.М. Кирова” Минобороны РФ. Слободяник Александр Валерьевич - канд. мед. наук, начальник хирургического отделения клиники кафедры госпитальной хирургии, ФГБВОУ ВО “Военномедицинская академия им. С.М. Кирова” Минобороны РФ. Кудрявцева Анна Владимировна - канд. мед. наук, заведующая рентгеновским отделением (компьютерная томография) кафедры рентгенологии и радиологии с курсом ультразвуковой диагностики, ФГБВОУ ВО “Военно-медицинская академия им. С.М. Кирова” Минобороны РФ. Железняк Игорь Сергеевич - доктор мед. наук, начальник кафедры рентгенологии и радиологии с курсом ультразвуковой диагностики, ФГБВОУ ВО “Военно-медицинская академия им. С.М. Кирова” Минобороны РФ. Котив Богдан Николаевич - доктор мед. наук, профессор, заместитель начальника академии по учебной и научной работе, ФГБВОУ ВО “Военно-медицинская академия им. С.М. Кирова” Минобороны РФ. Алентьев Сергей Александрович - доктор мед. наук, доцент кафедры общей хирургии, ФГБВОУ ВО “Военно-медицинская академия им. С.М. Кирова" Минобороны РФ. Лазуткин Максим Витальевич - доктор мед. наук, доцент кафедры общей хирургии ФГБВОУ ВО “Военно-медицинская академия им. С.М. Кирова” Минобороны РФ. Солдатов Сергей Анатольевич - старший ординатор хирургического отделения клиники кафедры госпитальной хирургии, ФГБВОУ ВО “Военно-медицинская академия им. С.М. Кирова” Минобороны РФ.
\end{abstract}

Для корреспонденции: Дзидзава Илья Игоревич - 194044, г. Санкт-Петербург, ул. Академика Лебедева, д. 6, Российская Федерация. Тел.: 8-911-247-39-23. E-mail: dzidzava@mail.ru

Dzidzava Il'ya Igorevich - Doct. of Med. Sci., Assistant Professor, Head of the Department of Hospital Surgery, Kirov Military Medical Academy. Slobodyanik Alexander Valerievich - Cand. of Med. Sci., Cheif of Surgical Department, Chair of Hospital Surgery, Kirov Military Medical Academy. Kudryavtseva Anna Vladimirovna - Cand. of Med. Sci., Cheif of the Department of X-ray (CT) Diagnosis, Chair of Radiology with the Course of Ultrasonography, Kirov Military Medical Academy. Zheleznyak Igor Sergeevich - Doct. of Med. Sci., Head of the Chair of Radiology with the Course of Ultrasonography, Kirov Military Medical Academy. Kotiv Bogdan Nikolaevich - Doct. of Med. Sci., Professor, Deputy Director of the Academy for Education and Research, Kirov Military Medical Academy. Alent'yev Sergey Alexandrovich - Doct. of Med. Sci., Assistant Professor of the Chair of General Surgery, Kirov Military Medical Academy. Lazutkin Maxim Vitalevich - Doct. of Med. Sci., Assistant Professor of the Chair of General Surgery, Kirov Military Medical Academy. Soldatov Sergey Anatolievich - Surgeon of the Surgical Department of the Clinic of Chair of Hospital Surgery, Kirov Military Medical Academy.

For correspondence: Dzidzava Il'ya Igorevich - 6, Lebedeva str., Saint-Petersburg, 194044, Russian Federation. Phone: +7-911-247-39-23. E-mail: dzidzava@mail.ru 
предиктор послеоперационной печеночной недостаточности характеризовался умеренной прогностической силой $(c$-statistic $=0,71, p=0,04)$ с чувствительностью и специфичностью 84,6 и $61 \%$ соответственно. Показатели элиминации индоцианина зеленого были достоверно хуже у больных хроническим заболеваниями печени или после повторных курсов полихимиотерапии: скорость плазменной элиминации индоцианина зеленого составила 15,6\%/мин по сравнению с 18,6\%/мин ( $p=0,004)$, остаточная концентрация индоцианина зеленого на 15 -й минуте - $19,6 \%$ по сравнению с $6,1 \%(p=0,003)$. Клиренс-тест с индоцианином зеленым характеризовался чувствительностью $92,3 \%$ и специфичностью $71,4 \%$ в определении функционального потенциала печени, а также превосходной прогностической силой ( $c$-statistic $=0,82 ; p=0,0001)$ в предопределении пострезекционной печеночно-клеточной недостаточности. Факторами риска печеночной недостаточности после обширных резекций признаны планируемый пострезекционный объем $<372 \mathrm{~cm}^{3} / \mathrm{M}^{2}$ и скорость плазменной элиминации индоцианина зеленого $<10 \% /$ мин. Показанием к предоперационной эмболизации воротной вены является будущий фрагмент печени $<372 \mathrm{~cm}^{3} / \mathrm{M}^{2}$ при скорости элиминации индоцианина зеленого $>15 \%$ /мин или скорость плазменной элиминации индоцианина зеленого $>10 \% /$ мин, но менее $15 \% /$ мин при планируемом пострезекционном объеме $<550 \mathrm{~cm}^{3} / \mathrm{M}^{2}$. Применение этих критериев позволило уменьшить частоту пострезекционной печеночной недостаточности $(25,6 \%)$ и исключить развитие ее тяжелых форм.

Заключение. Планируемый пострезекционный объем печени по данным КТ-волюметрии и параметры клиренс-теста с индоцианином зеленым являются высокочувствительными методами прогнозирования послеоперационной печеночно-клеточной недостаточности. Применение разработанного лечебно-диагностического алгоритма с уточненными показаниями к предоперационной эмболизации воротной вены позволяет уменьшить частоту пострезекционной печеночной недостаточности.

Ключевые слова: печень, резекция, эмболизация воротной вены, печеночная недостаточность, КТ-волюметрия, объем печени, функциональные тесты, индоцианин зеленый.

\title{
The Results of CT-Volumetry and Clearance Test with Indocyanine Green as Indications for Preoperative Portal Vein Embolization
}

\author{
Dzidzava I.I. ${ }^{1}$, Slobodyanik A.V.' , Kudryavtseva A.V. ${ }^{3}$, Zheleznyak I.S. ${ }^{3}$, \\ Kotiv B.N. ${ }^{1,2}$, Alent'yev S.A. ${ }^{2}$, Lazutkin M.V. ${ }^{2}$, Soldatov S.A. ${ }^{1}$ \\ ${ }^{1}$ Chair of Hospital Surgery, ${ }^{2}$ Chair of General Surgery, ${ }^{3}$ Chair of Radiology with the Course of Ultrasonography, \\ Kirov Military Medical Academy, Ministry of Defence of the Russian Federation; 6, Lebedeva str., \\ Saint-Petersburg, 194044, Russian Federation
}

\begin{abstract}
Aim. To clarify the indications for preoperative portal vein embolization using CT-volumetry and indocyanine green clearance as predictors of post-resection liver failure.

Material and Methods. The results of 179 liver resections were analyzed. There were 128 hemihepatectomies and 51 partial resections. In 24 cases preoperative portal vein embolization was used. Indocyanine green clearance test was applied for a quantitative assessment of liver function. Plasma disappearance rate and residual concentration of indocyanine green during the first 15 minutes were determined. CT-volumetry was used to calculate the future remnant liver volume. Posthepatectomy liver failure severity was evaluated in accordance with the recommendations of the International Study Group of Liver Surgery (ISGLS) and taking into account "50-50" criteria.

Results. The frequency of posthepatectomy liver failure after extensive resections was $42.5 \%$ : grade A - 38.7\%; grade B $41.9 \%$, grade $\mathrm{C}-19.4 \%$. The future remnant liver volume as a predictor of posthepatectomy liver failure had moderate predictive power $(c$-statistic $=0.71, p=0.04$ ) with sensitivity and specificity about $84.6 \%$ and $61 \%$, respectively. Indocyanine green elimination was significantly worse in patients with chronic liver disease or after previous repeated courses of chemotherapy (plasma disappearance rate $15.6 \% / \mathrm{min} v s 18.6 \% / \mathrm{min}, p=0.004$; indocyanine green residual concentration after 15 minutes $19.6 \%$ vs $6,1 \%, p=0.003$ ). Clearance test with indocyanine green was characterized by high sensitivity $(92.3 \%)$ and specificity $(71.4 \%)$ in the definition of liver function and excellent predictive power $(c$-statistic $=0.82, p=0.0001)$ in determining of posthepatectomy liver failure. Risk factors of posthepatectomy liver failure were future remnant liver volume $<372 \mathrm{~cm}^{3} / \mathrm{m}^{2}$ and plasma disappearance rate of indocyanine green $<10 \% / \mathrm{min}$. The indications for preoperative portal vein embolization are future remnant liver volume $<372 \mathrm{~cm}^{3} / \mathrm{m}^{2}$ at plasma disappearance rate of indocyanine green $>15 \% / \mathrm{min}$ or plasma disappearance rate of indocyanine green $>10 \% / \mathrm{min}$ but $<15 \% / \mathrm{min}$ and future remnant liver volume $<550 \mathrm{~cm}^{3} / \mathrm{m}^{2}$. These criteria allowed to reduce the incidence of posthepatectomy liver failure $(25.6 \%)$ and to avoid the development of severe liver dysfunction.

Conclusion. The future remnant liver volume and indocyanine green clearance test are highly sensitive methods to predict posthepatectomy liver failure. Application of the developed diagnostic and treatment algorithm with updated indications for preoperative portal vein embolization can reduce the frequency of posthepatectomy liver failure.
\end{abstract}

Key words: liver, resection, preoperative portal vein embolization, liver failure, CT-volumetry, liver volume, functional tests, indocyanine green. 


\section{Введение}

Резекция печени является главной составляющей комплексного лечения больных злокачественными новоообразованиями органов гепатопанкреатодуоденальной зоны. Совершенствование методов анестезиологического пособия, хирургической техники и инструментов значительно уменьшило частоту послеоперационных осложнений и периоперационную летальность. Однако основной причиной осложнений и летальности при обширных резекциях печени по-прежнему остается печеночно-клеточная недостаточность. Пострезекционная печеночная недостаточность (ППН) развивается в результате малого объема и (или) недостаточного функционального резерва будущего фрагмента печени, по данным различных авторов, в 45-75\% наблюдений [1-5]. Ошибочная трактовка объема и функции остающейся части печени может привести к неправильному выбору метода лечения - отказу от выполнения резекции или превышению объема оперативного вмешательства. Таким образом, точная оценка функциональной массы будущего фрагмента печени является важной задачей дооперационного обследования, особенно у больных с патологически измененной паренхимой органа [6].

В качестве эффективного метода увеличения планируемого пострезекционного объема (ППО) печени широкое признание получила предоперационная эмболизация воротной вены (ПЭВВ). Безопасность и эффективность метода подтверждены целым рядом современных исследований и метаанализов [7-9]. Эмболизация ветвей воротной вены вызывает атрофию ипсилатеральных сегментов с сопутствующей компенсаторной гипертрофией ППО печени. В настоящее время ПЭВВ рекомендуют, когда ППО составляет менее 30-40\% общего объема печени, в зависимости от сопутствующих поражений печени [10-15].

Эффективность регенерации печени, как правило, оценивается с помощью КТ-волюметрии. КТ-волюметрия позволяет получить исчерпывающую анатомо-топографическую информацию об остающемся фрагменте печени, но анатомический объем не тождественен функциональному объему, особенно у пациентов старшего возраста, после повторных курсов химиотерапевтического лечения, при наличии стеатоза, холестаза, фиброза, гепатита или цирроза печени [16-18]. Поэтому в ходе подготовки к резекционным вмешательствам обязательно следует определить функциональные резервы печени. Среди методов, используемых для оценки функции печени, наиболее часто используют широкий спектр серологических тестов и различные клинические скрининговые системы (Child-Pugh, MELD), которые позволяют грубо оценить риск планируемой операции. Более точными методами оценки функционального состояния печени являются различные клиренс-тесты (тест с индоцианином зеленым, галактозой, аминопирином, лидокаином и др.). Комбинация методов количественной функциональной и анатомической оценки будущего фрагмента печени позволяет получить более полную информацию для оценки риска хирургического вмешательства.

Цель исследования: анализ результатов КТволюметрии и клиренса индоцианина зеленого как факторов прогноза пострезекционной печеночной недостаточности и уточнение показаний к предоперационной эмболизации ветвей воротной вены.

\section{Материал и методы}

Проведен анализ результатов обследования и лечения 179 больных с различными новообразованиями печени. Мужчин было 85, женщин - 94. Средний возраст больных составил $54,1 \pm 8,2$ года. Все пациенты были разделены на две основные группы: 124 наблюдения составили группу ретроспективного анализа, 55 пациентов включены в проспективное исследование для апробации разработанного лечебно-диагностического алгоритма. В подавляющем большинстве наблюдений показанием к оперативному лечению служили злокачественные новообразования $(85,5 \%)$, в других наблюдениях резекцию печени предпринимали при доброкачественном ее поражении (табл. 1). Сопутствующие заболевания разной степени тяжести были у 96 больных. Ишемическая болезнь сердца диагностирована у $14(7,8 \%)$ больных, гипертоническая болезнь у 16 (8,9\%), сахарный диабет II типа - у 12 (6,7\%), заболевания нервной системы - у $3(1,7 \%)$, другие сопутствующие заболевания диагностированы у 16 (8,9\%) пациентов. У 12 больных было сочетание различных заболеваний. Наличие сопутствующих заболеваний в той или иной степени вносило вклад в общее состояние больных, зачастую способствовало осложнениям, ухудша-

Таблица 1. Распределение больныхпо нозологическим формам

\begin{tabular}{l|c}
\hline \multicolumn{1}{c|}{ Нозологическая форма } & $\begin{array}{c}\text { Число } \\
\text { наблю- } \\
\text { дений, } \\
\text { абс. }(\%)\end{array}$ \\
\hline Гепатоцеллюлярный рак & $38(21,2)$ \\
Внутрипеченочная холангиокарцинома & $13(7,3)$ \\
Рак проксимальных желчных протоков & $33(18,4)$ \\
Рак желчного пузыря & $7(3,9)$ \\
Метастазы колоректального рака & $56(31,3)$ \\
Метастазы других опухолей & $6(3,3)$ \\
Гемангиома & $23(12,8)$ \\
Альвеококкоз печени & $3(1,8)$ \\
\hline Итого & $179(100)$ \\
\hline
\end{tabular}


ло прогноз. У 47 (26,3\%) больных установлены сопутствующие хронические диффузные заболевания печени. Хронический вирусный гепатит В диагностирован у 15 больных, хронический вирусный гепатит С - у 23, сочетание вирусных гепатитов В и C - у 7, и в 2 наблюдениях выявлен цирроз печени невирусной этиологии. Многократные курсы (более 3) химиотерапии до операции получили $42(23,5 \%)$ пациента, из них в 16 наблюдениях препараты вводили регионарно, в 26 - системно.

В ретроспективной группе в 73 наблюдениях осушествлена обширная резекция печени, в $51-$ экономная резекция. В проспективной группе всем больным выполнена обширная резекция. Стратификация наблюдений в зависимости от объема оперативного вмешательства представлена на рис. 1. Резекция левого латерального сектора выполнена 27 (52,3\%) больным, резекция левого медиального сектора - $4(7,8 \%)$, бисегментэктомия $\mathrm{S}_{\mathrm{V}, \mathrm{VI}}-6(11,8 \%)$, резекция правого заднего сектора - $11(21,6 \%)$, сегментэктомия $\mathrm{S}_{\mathrm{VI}}-3(5,9 \%)$.

В 24 наблюдениях выполнена ПЭВВ: 10 наблюдений в ретроспективной группе и 14 - в проспективной. В 8 наблюдениях эту процедуру выполнили после масляной химиоэмболизации печеночной артерии, в 10 сочетали с масляной химиоэмболизацией воротной вены. Трем больным ПЭВВ выполнили повторно в связи с недостаточной гипертрофией предполагаемой культи печени.

Для оценки исходного функционального состояния печени использовали критерии ChildPugh и шкалу MELD (табл. 2 и 3).

Степень тяжести пострезекционной печеночной недостаточности определяли на 5-е сутки послеоперационного периода в соответствии с рекомендациями Международной исследовательской группы по хирургии печени (ISGLS) и с учетом критериев "50-50" (табл. 4) [19, 20].

Для количественной оценки функции печени проводили высокоселективный мониторинг элиминации из крови диагностического красителя - индоцианина зеленого (ИЦЗ). Определение концентрации красителя в крови выполняли методом пульсовой денситометрии с помощью неинвазивного сенсора аппарата LiMON PC5000 версия 1.4 фирмы PULSION Medical Systems AG (Германия). Водорастворимый краситель индоцианин зеленый вводили внутривенно непосредственно перед исследованием в дозе 0,5 мг/кг массы тела пациента. Продолжительность клиренс-теста составляла 15-20 мин. В ходе исследования определяли скорость плазменной элиминации индоцианина зеленого $\left(С П Э_{\text {ицз }}\right)$ и уровень остаточной концентрации ИЦЗ в плазме через 15 мин после введения (OK15 ицз). Нормальными показателями клиренс-теста,

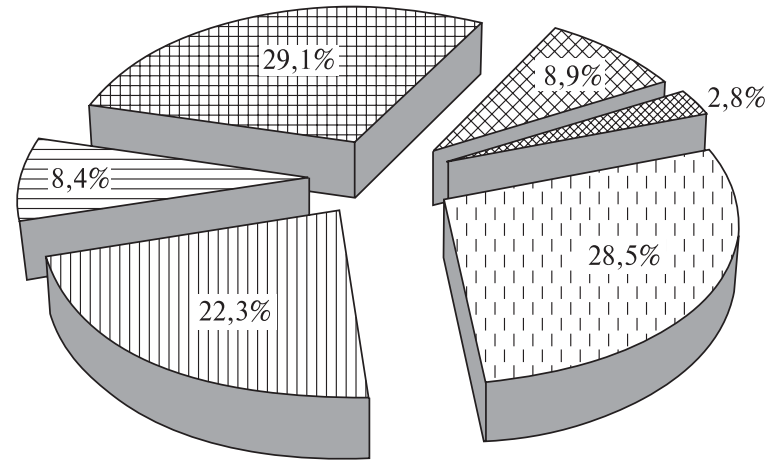

[1] Расширенная правосторонняя гемигепатэктомия

Расширенная левосторонняя гемигепатэктомия

Правосторонняя гемигепатэктомия

Левосторонняя гемигепатэктомия

Сочетание резекции 3 и более сегментов

Экономные резекции

Рис. 1. Диаграмма. Распределение больных в зависимости от объема резекции печени.

при которых функцию печени считали ненарушенной, являлись СПЭ ицз $20 \%$ миин и более, a OK15 ицз - менее $10 \%$ [21-23].

Для топической диагностики образований, определения распространенности онкологического процесса, изучения топографической анатомии афферентных и эфферентных сосудов печени, выявления измененных лимфатических узлов использовали МСКТ с внутривенным болюсным контрастным усилением без специальной подготовки. При постпроцессорной обработке изображений рассчитывали объемные характеристики: общий объем печени, объем образования, ожидаемый объем резекции и ППО культи печени. КТ-волюметрию выполняли

Таблица 2. Распределение пациентов по критериям Child-Pugh

\begin{tabular}{c|c}
\hline $\begin{array}{c}\text { Степень тяжести } \\
\text { дисфункции печени }\end{array}$ & $\begin{array}{c}\text { Число } \\
\text { наблюдений, } \\
\text { абс. }(\%)\end{array}$ \\
\hline Класс А & $104(58,1)$ \\
Класс В & $62(34,6)$ \\
Класс С & $13(7,3)$ \\
\hline Итого & $179(100)$ \\
\hline
\end{tabular}

Таблица 3. Распределение пациентов по шкале MELD

\begin{tabular}{c|c}
\hline $\begin{array}{c}\text { Степень тяжести } \\
\text { дисфункции печени }\end{array}$ & $\begin{array}{c}\text { Число } \\
\text { наблюдений, } \\
\text { абс. }(\%)\end{array}$ \\
\hline MELD 0-13 баллов & $156(87,2)$ \\
MELD $\geqslant 14$ баллов и более & $33(12,8)$ \\
\hline Итого & $179(100)$ \\
\hline
\end{tabular}


Таблица 4. Рекомендации ISGLS для определения тяжести пострезекционной печеночной недостаточности

\begin{tabular}{|c|c|c|c|}
\hline & Степень А & Степень В & Степень С \\
\hline $\begin{array}{l}\text { Специфическое } \\
\text { лечение }\end{array}$ & Не требуется & $\begin{array}{l}\text { Свежезамороженная плазма, } \\
\text { альбумин, диуретики, } \\
\text { неинвазивная вентиляция, } \\
\text { лечение в палате интенсивной } \\
\text { терапии }\end{array}$ & $\begin{array}{l}\text { Лечение в палате } \\
\text { интенсивной терапии, } \\
\text { вазоактивная терапия, } \\
\text { коррекция углеводного } \\
\text { обмена, гемодиализ } \\
\text { и экстракорпоральные } \\
\text { методы поддержки печени, } \\
\text { интубация и ИВЛ }\end{array}$ \\
\hline Функция печени & $\begin{array}{l}\text { МНО <1,5 (ПТИ >50\%), } \\
\text { билирубин }<50 \text { ммоль } / \text { л, } \\
\text { неврологической } \\
\text { симптоматики нет }\end{array}$ & $\begin{array}{l}1,5<\text { МНО }<2,0 \text { (ПТИ <50\%), } \\
\text { билирубин }>50 \text { ммоль/л, } \\
\text { начальные признаки } \\
\text { неврологического дефицита } \\
\text { (вялость, сонливость, } \\
\text { заторможенность, спутанность } \\
\text { сознания) }\end{array}$ & $\begin{array}{l}\text { МНО >2,0, билирубин } \\
>100-120 \text { ммоль/л, } \\
\text { выраженный (тяжелый) } \\
\text { неврологический дефицит, } \\
\text { печеночная энцефалопатия }\end{array}$ \\
\hline Функция почек & $\begin{array}{l}\text { Адекватный темп } \\
\text { диуреза }(>50 \text { мл/кг/ч), } \\
\text { мочевина }<150 \text { мг/дл, } \\
\text { нет признаков уремии }\end{array}$ & $\begin{array}{l}\text { Снижен темп диуреза } \\
(<50 \text { мл/кг/ч), } \\
\text { мочевина <150 мг/дл, } \\
\text { нет признаков уремии }\end{array}$ & $\begin{array}{l}\text { Почечная недостаточность, } \\
\text { неэффективность терапии } \\
\text { диуретиками, } \\
\text { мочевина > } 150 \text { мг/дл, } \\
\text { симптомы уремии }\end{array}$ \\
\hline $\begin{array}{l}\text { Функция } \\
\text { дыхания }\end{array}$ & $\begin{array}{l}\text { Сатурация кислородом } \\
\text { артериальной крови } \\
>90 \%, \text { кислород может } \\
\text { дополнительно } \\
\text { подаваться через } \\
\text { носовые канюли }\end{array}$ & $\begin{array}{l}\text { Сатурация кислородом } \\
\text { артериальной крови <90\%, } \\
\text { несмотря на подачу кислорода } \\
\text { через носовые канюли } \\
\text { или маску }\end{array}$ & $\begin{array}{l}\text { Тяжелая, рефрактерная } \\
\text { гипоксемия <85\% с высокой } \\
\text { фракцией кислорода во } \\
\text { вдыхаемой смеси }\end{array}$ \\
\hline $\begin{array}{l}\text { Дополнительная } \\
\text { диагностика }\end{array}$ & Не требуется & $\begin{array}{l}\text { УЗИ, КТ живота и головного } \\
\text { мозга, рентгенография легких, } \\
\text { посев крови, мочи, мокроты }\end{array}$ & $\begin{array}{l}\text { УЗИ, КТ груди, живота } \\
\text { и головного мозга, посевы } \\
\text { биосред, мониторинг } \\
\text { внутричерепного давления }\end{array}$ \\
\hline
\end{tabular}

в ручном режиме: обведение контура печени на каждом КТ-срезе; введение диапазона плотностных показателей (плотность паренхимы печени); расчет требуемых объемных параметров в абсолютных величинах $\left(\mathrm{cm}^{3}\right)$ программным обеспечением по интегральной формуле Симпсона. С учетом различия в конституции и физическом развитии больных для более точного расчета планируемого пострезекционного остатка паренхимы объем печени пересчитывали на площадь поверхности тела $\left(\mathrm{M}^{2}\right)$ :

$$
\mathrm{V}\left(\mathrm{CM}^{3} / \mathrm{M}^{2}\right)=\mathrm{V}\left(\mathrm{CM}^{3}\right) / \operatorname{BSA}\left(\mathrm{M}^{2}\right),
$$

где BSA (body surface area) - площадь поверхности тела $\left(\mathrm{BSA}=0,007184 \times\left(\right.\right.$ масса,$[\mathrm{K}]_{0,425} \times$ рост $\left.[\mathrm{cm}]_{0,725}\right)$.

Для расчета планируемого пострезекционного объема печени в относительных показателях применяли формулу:

$$
\text { ППО }(\%)=[\Pi \Pi О /(\text { ОП - ОО })] \times 100 \%,
$$

где ППО - планируемый пострезекционный объем печени, ОП - общий объем печени, ОО объем опухоли.

В наблюдениях с предоперационной эмболизацией воротной вены через 28 дней выполняли повторную КТ-волюметрию с оценкой степени викарной гипертрофии контрлатеральной доли печени. Прирост объема планируемого пострезекционного объема печени (\%) рассчитывали по формуле:

$$
\begin{aligned}
& \text { ПрППО }(\%)=[(\text { ППО } \\
& \text { ППО до Пэвв }] \times 100 \text {, }
\end{aligned}
$$

где ПрППО - прирост объема ППО, ПЭВВ предоперационная эмболизация воротной вены.

Статистическую обработку результатов проводили с помощью прикладных программ Microsoft Excel 7.0 и Statistica 8.0 для Windows. Использовали методы описательной статистики, сравнительного анализа с применением непараметрических критериев Манна-Уитни, Колмогорова-Смирнова, Краскела-Уоллиса, Спирмена, Фридмана и конкордации Кендалла. Количественные значения представлены медианой и нижним и верхним квартилями. Анализ точности и практической ценности прогностических факторов и валидность моделей измеряли способом конкордантной статистики - оценкой площади под ROC-кривой. ROC-кривые представляли собой характеристические кривые соотношения "чувствительность/специфичность" и отражали различающую способность метода в целом. Величина площади под кривой от 0,8 
Таблица 5. Объемные и функциональные характеристики печени у больных ретроспективной группы

\begin{tabular}{l|c|c|c}
\hline \multicolumn{1}{c|}{ Характеристика } & Обширная резекция & Экономная резекция & $p$ \\
\hline Общий объем печени, см ${ }^{3} / \mathrm{M}^{2}$ & $1393[1035-1498]$ & $1289[940-1378]$ & 0,19 \\
Планируемый объем резекции, см ${ }^{3} / \mathrm{M}^{2}$ & $754[613-820]$ & $233[166-304]$ & 0,001 \\
ППО, см ${ }^{3} \mathrm{M}^{2}$ & $542[492-736]$ & $897[780-935]$ & 0,004 \\
ППО,\% & $32[19-41]$ & $68[64-78]$ & 0,001 \\
Скорость плазменной элиминации ИЦ3, \%/мин & $18,4[15,1-20,5]$ & $22,6[14,5-25,4]$ & 0,11 \\
Остаточная концентрация ИЦЗ на 15-й минуте, \% & $6,5[5-12,1]$ & $4,2[3,1-17]$ & 0,22 \\
\hline
\end{tabular}

Примечание: все характеристики даны в виде медианы (см. “Материал и методы”); в квадратных скобках указаны нижний и верхний квартили.

до 0,9 свидетельствовала о превосходной диагностической точности, 0,7-0,8 - об умеренной, а менее 0,7 - о низкой прогностической силе.

\section{Результаты}

Различные послеоперационные осложнения развились в $66(53,2 \%)$ наблюдениях ретроспективной группы (из них только у 4 (7,8\%) больных в группе малых резекций). Наиболее часто наблюдалась различной степени тяжести пострезекционная печеночная недостаточность. Частота ППН среди обширных резекций составила 42,5\%. Из них степень А составила 12 (38,7\%) наблюдений, степень В - 13 (41,9\%), степень С - $6(19,4 \%)$ наблюдений. Реже выявляли ассоциированный правосторонний гидроторакс, потребовавший дренирования плевральной полости, $-8(6,5 \%)$ пациентов, гнойно-септические осложнения - 3 (2,4\%) наблюдения, прочие осложнения отмечены у 4 (3,2\%) больных. Летальность составила 6,5\%.

Средний объем планируемой резекции печени, рассчитанный по данным компьютерной томографии, в группе больных с обширными вмешательствами составил $754 \mathrm{~cm}^{3} / \mathrm{M}^{2}$ [613-820], а в группе с малыми резекциями - $233 \mathrm{~cm}^{3} / \mathrm{M}^{2}$ [166-304] (табл. 5). Средний планируемый пострезекционный объем в группе с обширными вмешательствами составил $542 \mathrm{~cm}^{3} / \mathrm{M}^{2}$ [492-736] и был достоверно меньше, чем в группе с малыми резекциями - $897 \mathrm{~cm}^{3} / \mathrm{M}^{2}$ [780-935] ( $\left.p=0,004\right)$.

Следует отметить, что у 10 больных из группы обширных резекций печени по результатам КТволюметрии ППО в среднем составил 21\% от общего объема печени (348 см с $^{3} \mathrm{M}^{2}$ [182-406]), что потребовало выполнения предоперационной эмболизации воротной вены. Планируемый пострезекционный объем через 28 дней увеличился до $508 \mathrm{~cm}^{3} / \mathrm{M}^{2}$ [371-586] (31\%). Таким образом, в среднем прирост ППО составил $46 \%$.

При сопоставлении результатов обширных резекций с данными КТ-волюметрии установлено, что у больных с развившейся печеночноклеточной недостаточностью пострезекционный объем печени составил 372 см $^{3} / \mathrm{M}^{2}$ [351-550] при исходно функционально ослабленном органе $454 \mathrm{~cm}^{3} / \mathrm{M}^{2}$ [386-543] ( $\left.p=0,043\right)$, а у больных с не- осложненным послеоперационным периодом $580 \mathrm{~cm}^{3} / \mathrm{M}^{2}$ [484 - 736] ( $p=0,041$, рис. 2).

Для определения возможности применения планируемого пострезекционного объема печени в прогнозировании ППН анализирована характеристическая кривая соотношения "чувствительность/специфичность”. Результаты КТволюметрии печени демонстрировали умеренную прогностическую силу (c-statistic $=0,710$, $p=0,04)$ с чувствительностью и специфичностью 84,6 и $61 \%$ соответственно (рис. 3). В качестве пороговых критериев выбраны значения медианы и верхнего квартиля ППО в группе больных с пострезекционной печеночной недостаточностью - 372 и $550 \mathrm{~cm}^{3} / \mathrm{M}^{2}$. Установлено, что у больных с будущим фрагментом печени менее $372 \mathrm{~cm}^{3} / \mathrm{M}^{2}$ ухудшение функции печени отмечено во всех наблюдениях, а при ППО более $550 \mathrm{~cm}^{3} / \mathrm{M}^{2}$ - лишьв 14,3\% (рис.4). Промежуточную группу с неясным прогнозом составили пациенты с остаточным объемом печени $372-550 \mathrm{~cm}^{3} / \mathrm{M}^{2}-$ послеоперационный период осложнился печеночной недостаточностью практически в половине наблюдений.

Для оценки функционального состояния печени до операции использовали результаты клиренс-теста с индоцианином зеленым. У обследованных пациентов ретроспективной группы СПЭ (18,8 [14,9-22]), а ОК15 ицз находилась в диапазоне от 0,5 до $50,9 \%$ (6 [4,1-17,0]). Скорость плазменной элиминации ИЦЗ коррелировала с активностью АлАТ $(r=-0,58 ; p<0,05)$ и АсАТ $(r=-0,45 ; p<0,05)$, уровнем общего билирубина $(r=-0,41, p<0,05)$ и креатинина $(r=-0,44$, $p<0,05)$. Не отмечено связи параметров клиренс-теста с уровнем общего белка и его фракциями, протромбиновым временем и уровнем фибриногена плазмы крови. С нарастанием тяжести печеночно-клеточной недостаточности, согласно критериям Child-Pugh и баллам MELD, показатели клиренса индоцианина прогрессивно ухудшались $\left(r_{\text {Child }}=-0,54, p<0,05 ; r_{\mathrm{MELD}}=-0,65\right.$, $p<0,05)$.

При сравнительном анализе параметров динамического теста с индоцианином зеленым достоверных различий между группами обширных 
и малых резекций не установлено $\left(p_{\text {спэицз }}=0,11\right.$; $p_{\text {ОК15ицз }}=0,22$, см. табл. 5), т.е. объем поражения значимо не влияет на функциональное состояние печени. Однако необходимо отметить, что в исследование не включали пациентов с субтотальным и тотальным поражением печени, что могло бы сказаться на результатах клиренс-теста.

Показатели элиминации ИЦЗ были достоверно хуже у больных хроническими заболеваниями печени или после повторных курсов полихимиотерапии (СПЭ ицз 15,6 и 18,6\%/мин; $p=0,004$; OK $15_{\text {ицз }} 19,6$ и $\left.6,1 \% ; p=0,003\right)$. Полученные результаты наглядно подтверждают, что наличие хронического диффузного поражения печени приводит к уменьшению функционального печеночно-клеточного резерва и является одним из прогностически неблагоприятных признаков.

Низкие параметры клиренса индоцианина зеленого являлись фактором риска развития пострезекционной печеночной недостаточности. У больных с развившейся пострезекционной дисфункцией СПЭ ицз была меньше, а OK $15_{\text {ицз }}$ больше, чем в наблюдениях с неосложненным послеоперационным периодом $($ СПЭ ицз $15,1 \%)$ мин в сравнении с 20,3\%/мин; ОК15 ицз 17,1 и $5,1 \% ; p=0,001$ ) (рис. 5). При ROC-анализе скорость плазменной элиминации ИЦЗ демонстрировала достоверно высокую чувствительность (92,3\%) и специфичность $(71,4 \%)$ в определении функционального потенциала печени и обладала превосходной прогностической силой (c-statistic = $0,82, p=0,0001)$ в предопределении послеоперационной печеночной недостаточности (рис. 6). Пороговыми значениями являлись СПЭЭ 15\%/мин (частота ППН при достаточном ППО составляла $13,5 \%$ ) и менее $10 \%$ мин (ППН развилась в 85,7\% наблюдений). Скорость плазменной элиминации ИЦЗ в пределах 10-14\%/мин сопровождалась пострезекционной депрессией функции органа практически в половине наблюдений (рис. 7).

При сравнительном анализе КТ-волюметрии с параметрами клиренс-теста с индоцианином зеленым установлено, что определение скорости плазменной элиминации ИЦЗ превосходит по своей прогностической силе КТ-волюметрию печени (рис. 8). Однако статистически достоверных отличий между методами не получено ( $p=$ 0,43), что делает целесообразным для прогнозирования послеоперационной печеночной недостаточности использование обоих методов.

Исходя из полученных результатов, абсолютными факторами риска развития печеночной недостаточности после обширной резекции считаем ППО менее $372 \mathrm{~cm}^{3} / \mathrm{M}^{2}$ и СПЭ ицз менее

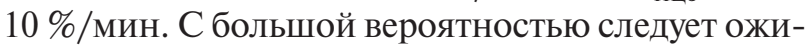
дать развития печеночно-клеточной недостаточности при объеме будущего фрагмента печени менее $550 \mathrm{~cm}^{3} / \mathrm{M}^{2}$ на фоне сниженного клиренса

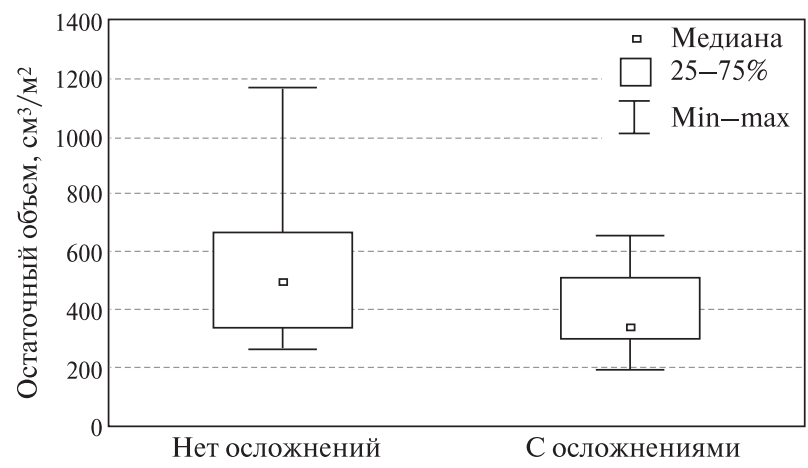

Рис. 2. Диаграмма. Планируемый пострезекционный объем печени в группах больных с послеоперационной печеночно-клеточной недостаточностью и неосложненным послеоперационным периодом.

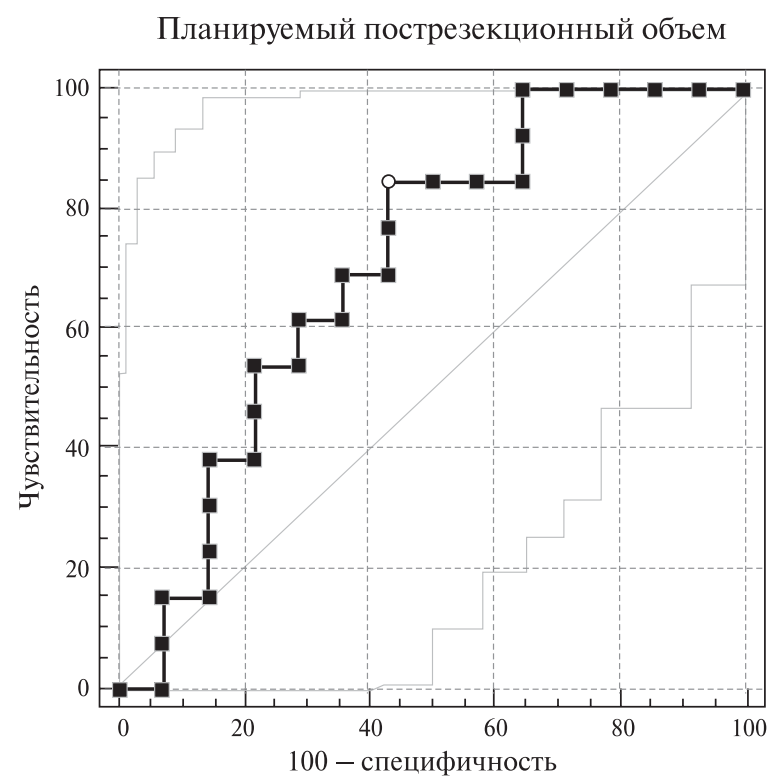

Рис. 3. Диаграмма. Соотношение чувствительности и специфичности КТ-волюметрии в определении планируемого пострезекционного объема печени.

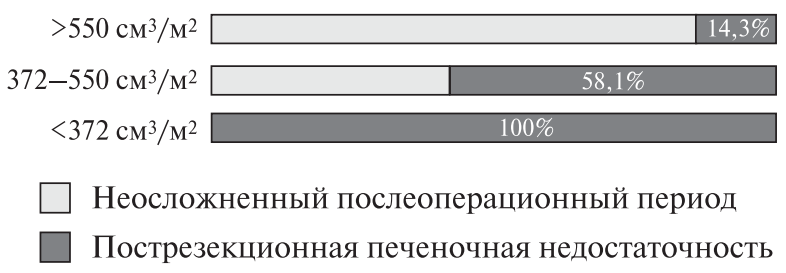

Рис. 4. Диаграмма. Зависимость частоты пострезекционной печеночной недостаточности от ППО. 

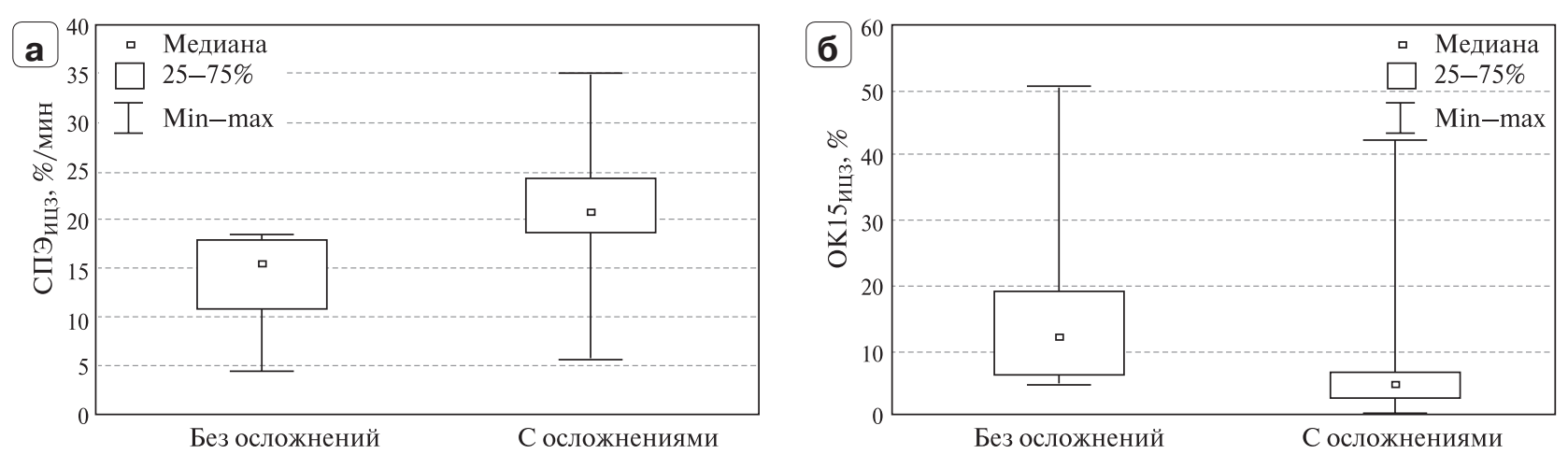

Рис. 5. Диаграмма. Параметры клиренса индоцианина зеленого в группах больных с послеоперационной печеночной недостаточностью и неосложненным послеоперационным периодом: а - скорость плазменной элиминации ИЦ3; 6 остаточная концентрация ИЦЗ на 15-й минуте.
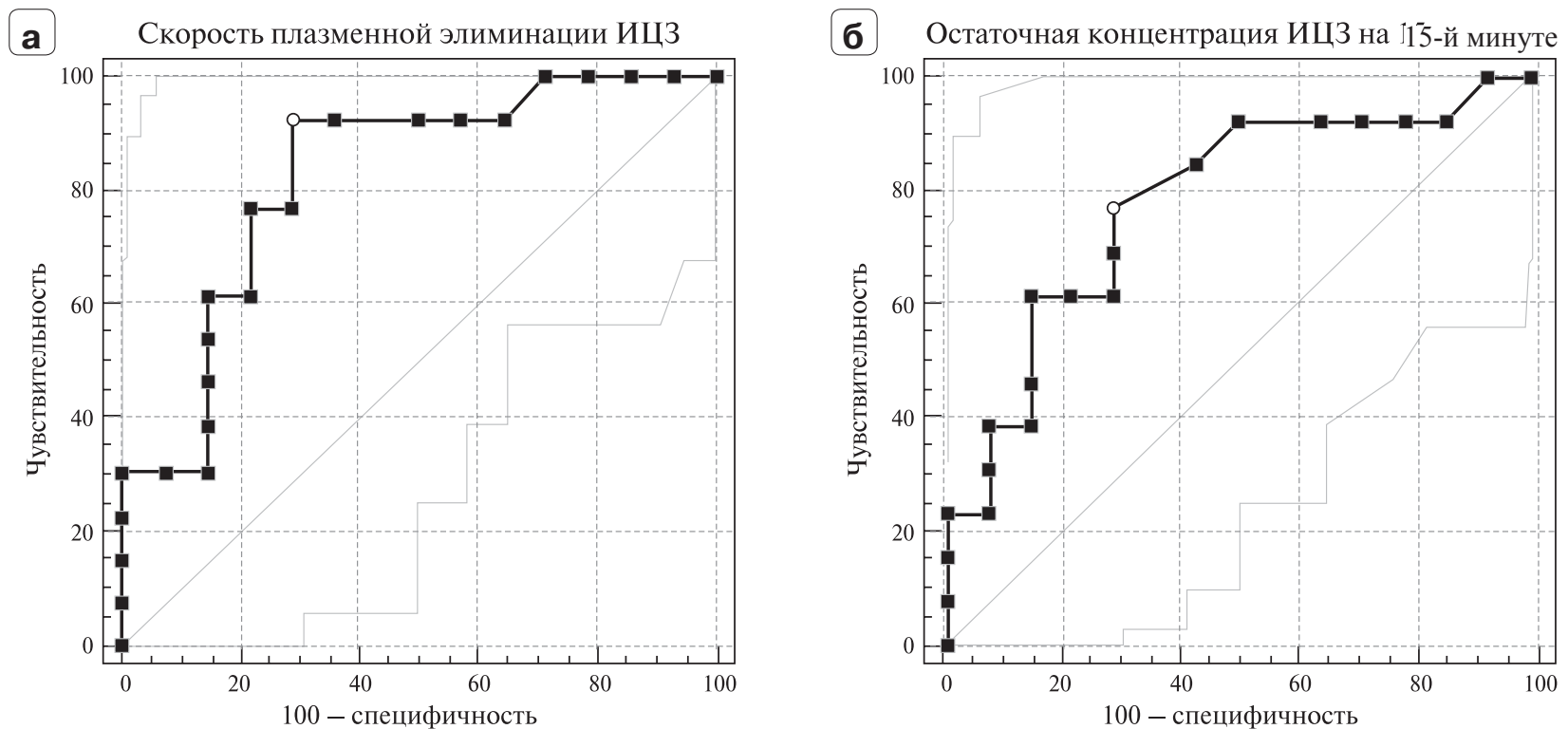

Рис. 6. Диаграмма. Соотношение чувствительности и специфичности параметров клиренса ИЦЗ: а - скорость плазменной элиминации ИЦ3; б - остаточная концентрация ИЦ3 на 15-й минуте.

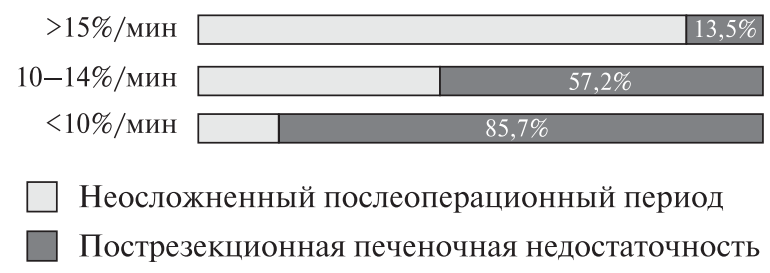

Рис. 7. Диаграмма. Зависимость частоты пострезекционной печеночной недостаточности от скорости плазменной элиминации ИЦЗ. 


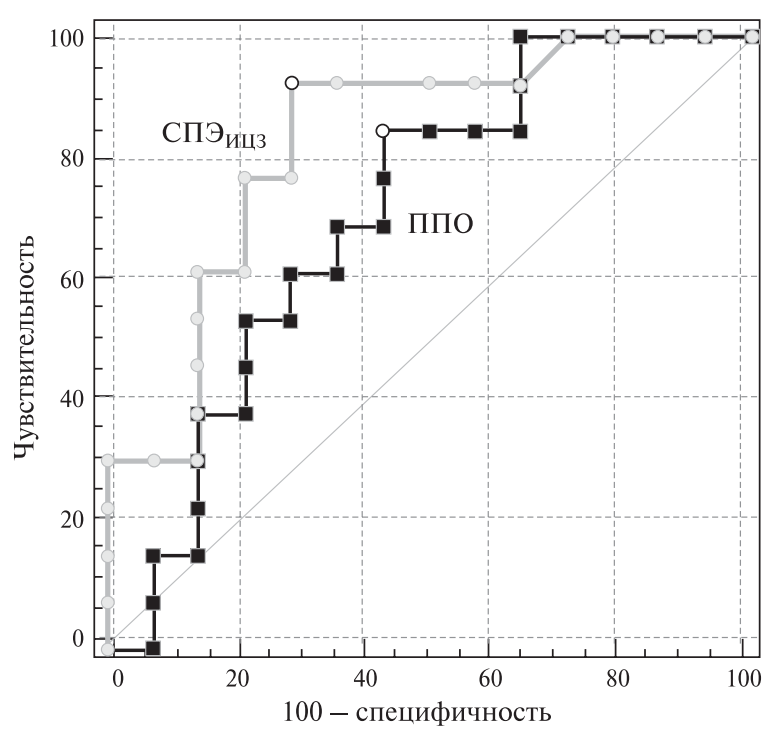

Рис. 8. Диаграмма. Сравнительный анализ ROC-кривых скорости плазменной элиминации ИЦЗ и ППО печени.

ИЦ3 (менее 15\%/мин). Эти критерии легли в основу уточненных показаний к предоперационной эмболизации воротной вены (рис. 9).

Разработанный алгоритм применен при обследовании 55 больных первичным раком печени и метастазами опухолей других органов. Во всех наблюдениях планировали обширный объем резекции. В проспективную группу не включали больных с крайне низкими показателями скорости элиминации ИЦЗ (менее 10\%/мин), поскольку в таких ситуациях считаем возможным выполнять только экономную резекцию или миниинвазивную локальную деструкцию опухоли в сочетании с полихимиотерапией. Из отобранных пациентов в 25 наблюдениях отмечены удовлетворительные параметры клиренса индоцианина зеленого (СПЭ емого пострезекционного объема печени $\left(\right.$ ПО $\left.>372 \mathrm{~cm}^{3} / \mathrm{M}^{2}\right)$. В 17 наблюдениях функциональные резервы печени были умеренно сниже- ны $\left(15>\right.$ СПЭ $_{\text {ицз }}>10 \%$ мин $)$ при достаточном ППО (>550 см $\left.{ }^{3} / \mathrm{M}^{2}\right)$. Показания к предоперационной эмболизации воротной вены были сформулированы у 14 больных. В 9 наблюдениях планируемый пострезекционный объем был меньше $372 \mathrm{~cm}^{3} / \mathrm{M}^{2}$ при СПЭ ишз более $15 \% /$ мин, а в 5 наблюдениях при ППО $<550 \mathrm{~cm}^{3} / \mathrm{M}^{2}$ скорость элиминации ИЦЗ была меньше 15\%/мин. Результатом ПЭВВ стал прирост будущего фрагмента печени на $133 \mathrm{~cm}^{3} / \mathrm{M}^{2}$, или 41\%. В послеоперационном периоде печеночная недостаточность развилась в $25,6 \%$ наблюдений: степень А - 9 наблюдений, степень В - 5. Развития тяжелой пострезекционной печеночно-клеточной недостаточности не отметили. Летальность составила $3,6 \%$.

\section{Обсуждение}

Несмотря на значимое сокращение послеоперационных осложнений и летальности при резекциях печени в большинстве крупных медицинских центров, пострезекционная печеночная недостаточность остается наиболее частым жизнеугрожающим осложнением. Планируемый пострезекционный объем и предоперационная оценка функционального резерва печени тесно коррелируют с развитием печеночной недостаточности при обширных резекциях, особенно у больных с патологически измененной функцией органа [1-5, 24].

В настоящее время спиральная КТ является стандартным методом диагностики. КТ-волюметрия, обеспечивая трехмерное изображение, позволяет хирургам имитировать удаление опухоли, вычислить объем резекции и оценить риск операции [25-28]. Оценка риска резекции строится на расчете объема печени после резекции. Выполнение обширных резекций считается возможным, если отношение будущего фрагмента печени к общему объему печени не меньше 25-30\%, а у больных с патологически измененной функцией печени - не менее 40\% [10-15, 27,

Клиренс-тест с индоцианином зеленым

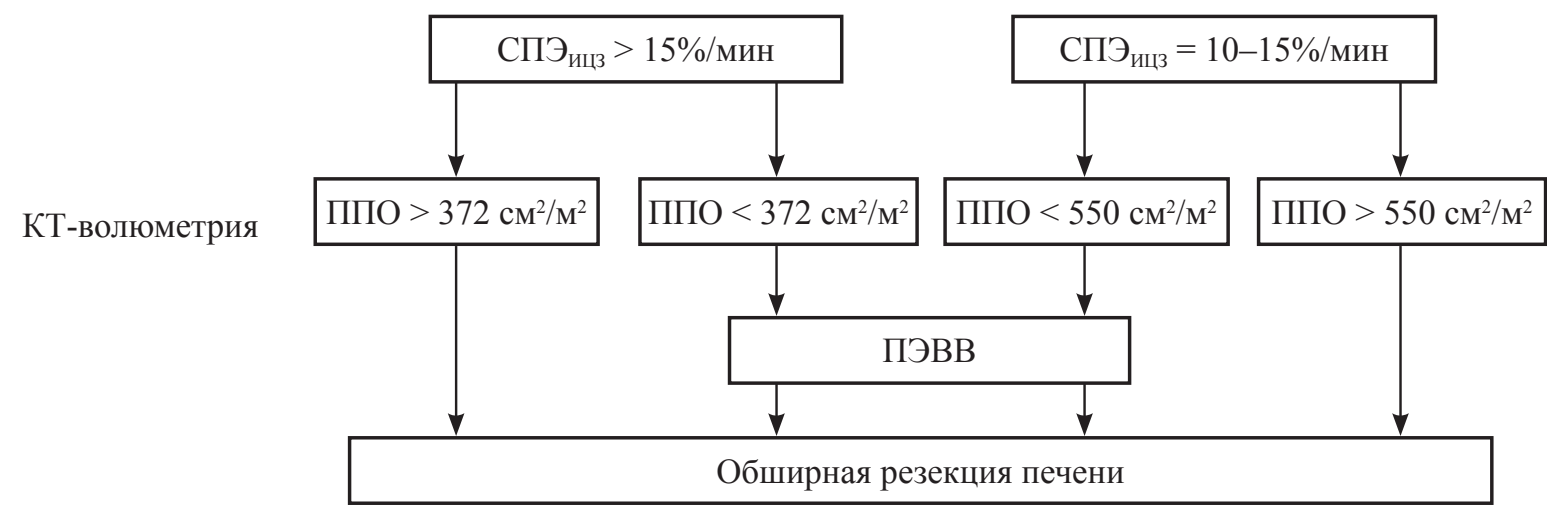

Рис. 9. Диаграмма. Алгоритм определения показаний к предоперационной эмболизации воротной вены и обширной резекции печени. 
28]. В проведенном исследовании удалось увеличить прогностическую точность КТ-волюметрии путем применения индивидуализированных количественных показателей объемных характеристик в пересчете на площадь поверхности тела. Установлено, что пороговыми значениями являются пострезекционные объемы печени 372 и $550 \mathrm{~cm}^{3} / \mathrm{M}^{2}$ с риском развития послеоперационной печеночной недостаточности 100 и 14,3\% соответственно. Тем не менее диагностическая ценность метода обладала умеренной прогностической силой, что еще раз доказывает: объем печени совсем не отражение ее функции. Таким образом, КТ-волюметрия может применяться для предоперационного расчета объема резецированных сегментов, но не демонстрирует функциональное состояние пораженной паренхимы.

Оценка функционального состояния печени по-прежнему представляет собой крайне трудную и далеко не решенную проблему. С этой целью применяют традиционные биохимические показатели, критерии Child-Pugh, баллы MELD, количественные клиренс-тесты. Каждый из них играет важную роль в прогнозировании ППН и уменьшении риска резекции печени.

Интерпретация биохимических показателей, с одной стороны, позволяет прямо или косвенно оценить тяжесть патологических процессов в печени. С другой стороны, по результатам целого ряда исследований, использование различных серологических параметров является, по крайней мере, противоречивым и не позволяет достоверно судить о тяжести (агрессивности) поражения печени и не может гарантировать функциональную полноценность органа [22, 29-35].

Критерии Child-Pugh - часто применяемый способ оценки функционального состояния печени, особенно при обследовании больных с опухолями печени на фоне цирроза. Основными преимуществами шкалы являются ее “глобальность”, комплексность в оценке функции печени и простота применения в повседневной клинической практике [31-33, 36, 37]. Главным недостатком шкалы является невозможность показать, какой объем печени можно безопасно удалить при конкретном числе баллов. Считают, что резекция печени достаточно безопасна при классе А по шкале Child-Pugh и не может быть рекомендована больным с печеночной недостаточностью класса С. У пациентов с субкомпенсированной дисфункцией печени (класс В) можно ожидать различные исходы резекции. Кроме того, оценка отдельных параметров носит субъективный качественный характер, а используемое деление лабораторных параметров на три группы неравномерно и произведено эмпирически. Поскольку каждый класс представляет собой совокупность нескольких показателей, фактическая функция печени может отличаться у паци- ентов с одинаковым числом баллов. Необходимо отметить, что параметры шкалы легко подвергаются воздействию внешних факторов. Наконец, нередко оценить тяжесть нарушений функции печени по шкале Child-Pugh невозможно у больных без цирроза с незначительным или умеренным угнетением функции печени. Такие противоречия уменьшают прогностическую точность шкалы и ограничивают ее применение для предсказания послеоперационной дисфункции печени $[23,33,35,38]$.

Ограничения критериев Child-Pugh привели к разработке шкалы MELD и ее модификаций. Шкала MELD первоначально разработана для определения прогноза у больных, перенесших TIPS, но впоследствии стала применяться у всех пациентов с диффузными заболеваниями печени при планировании хирургического вмешательства. Современными исследованиями доказано, что MELD позволяет предсказать выживаемость больных с терминальной стадией заболевания печени, но не способна определить прогноз резекции печени. В настоящее время шкалу применяют только для оценки тяжести и прогноза хронических заболеваний печени у пациентов, ожидающих трансплантации [31, 34, 38-40].

Поскольку ряд лекарственных средств метаболизируется почти исключительно печеночной системой цитохрома Р450, измерение их основных метаболитов будет отражать функциональное состояние печени. Примером могут служить тест элиминации галактозы, определение метаболитов лидокаина, аминопириновый дыхательный тест, тест элиминации сорбитола, фенилаланиновый дыхательный тест. Перечисленные методы являются непрямым отражением метаболической активности печени, зависят от функционального состояния системы цитохрома Р450 и тяжести нарушений портопеченочного кровообращения. В связи с этим рекомендуется комбинировать их с другими маркерами функционального состояния печени и не использовать в качестве самостоятельных методов прогнозирования безопасности резекции печени [41-46].

Клиренс-тест с индоцианином зеленым является широко распространенным количественным тестом функционального состояния печени. ИЦЗ представляет собой растворимое в воде инертное анионное соединение. После внутривенного введения он в течение 2-3 мин равномерно распределяется в крови, связываясь с альбумином, $\alpha 1-$ и $\beta$-липопротеинами, и затем селективно поглощается гепатоцитами. Весь диагностический краситель, захваченный печенью в неизмененном виде, выводится из организма с желчью при помощи АТФ-зависимой транспортной системы. В целом, клиренс ИЦЗ позволяет одновременно оценить несколько функций печени [21-23, 47-49]. Однако и у этого 
метода есть недостатки. Поскольку клиренс ИЦЗ зависит от печеночного кровотока, наличие внутри- и внепеченочных портокавальных коллатералей может оказать влияние на результаты теста.

Скорость плазменной элиминации ИЦЗ значительно уменьшена у больных с хроническим диффузным заболеванием печени в сравнении со здоровыми субъектами. Остаточная концентрация ИЦ3 на 15-й минуте более 15\% является фактором высокого риска развития тяжелых пострезекционных осложнений и требует выполнения максимально органосохраняющей резекции $[50,51]$. Поскольку динамический тест с индоцианином зеленым является недорогим, легко выполнимым и оператор-независимым, его широко используют для оценки функционального резерва печени. В Японии определение клиренса ИЦЗ является одним из главных методов тестирования функции печени до операции. По мнению H. Imamura и соавт. [48], у больных гепатоцеллюлярной карциномой без асцита и с нормальным уровнем билирубина остаточная концентрация ИЦ3 на 15-й минуте является основным фактором, определяющим резектабельность. Например, правосторонняя гемигепатэктомия считается безопасной при ОК $15_{\text {ицз }}<10 \%$. Левосторонняя гемигепатэктомия, правая медиальная или латеральная секторэктомия могут быть выполнены больным с ОK15 ицз в пределах 10-19\%. При OK15 ицз 20-29\% резекция печени должна быть ограничена сегментэктомией. Собственный опыт применения количественного клиренс-теста с индоцианином зеленым для оценки функции печени показал высокую диагностическую ценность метода (c-statistic $=0,82 ; p=0,0001)$. Установленные прогностические критерии пострезекционной печеночной недостаточности обладали высокой чувствительностью и специфичностью - 92,3 и 71,4\% соответственно. Резкое снижение темпа элиминации ИЦЗ (менее $10 \% /$ мин) являлось абсолютным фактором риска развития тяжелой ППН (степень С). При СПЭ ицз более $15 \% /$ мин частота послеоперационной дисфункции печени при достаточном ППО составила $13,5 \%$.

Таким образом, в идеале оценка функции печени должна включать как анатомическую, так и физиологическую составляющую. С этой целью попытались комбинировать результаты КТволюметрии и клиренс-теста с индицианином зеленым и на основании обоих методов уточнить показания к предоперационной эмболизации воротной вены - эффективному способу профилактики пострезекционной печеночной недостаточности. Такими критериями являются сочетание планируемого пострезекционного объема печени менее $372 \mathrm{~cm}^{3} / \mathrm{M}^{2}$ при скорости плазменной элиминации ИЦЗ более $15 \% /$ мин и СПЭ ицз $10-15 \% /$ мин при ППО менее $550 \mathrm{~cm}^{3} / \mathrm{m}^{2}$.
Внедрение установленных показаний к ПЭВВ при планировании обширных резекций позволило уменьшить частоту и тяжесть пострезекционной печеночной недостаточности.

\section{Заключение}

Определение планируемого пострезекционного объема печени по данным КТ-волюметрии и клиренс-тест с индоцианином зеленым являются высокочувствительными методами прогнозирования послеоперационной печеночно-клеточной недостаточности. Абсолютными факторами риска пострезекционной депрессии функции печени являются ППО печени (FRLV) менее $372 \mathrm{~cm}^{3} / \mathrm{M}^{2}$ и скорость элиминации ИЦ3 менее 10\%/мин. Применение разработанного лечебнодиагностического алгоритма планирования обширных резекций печени с уточненными показаниями к предоперационной эмболизации воротной вены позволяет уменьшить частоту пострезекционной печеночной недостаточности.

\section{Список литературы / References}

1. Fujii Y., Shimada H., Endo I., Morioka D., Nagano Y., Miura Y., Tanaka K., Togo S. Risk factors of posthepatectomy liver failure after portal vein embolization. J. Hepatobiliary Pancreat. Surg. 2003; 10 (3): 226-232. PMID: 14605980.

doi: $10.1007 / \mathrm{s} 00534-002-0820-9$.

2. Allemann P., Demartines N., Bouzourene H., Tempia A., Halkic N. Long-term outcome after liver resection for hepatocellular carcinoma larger than $10 \mathrm{~cm}$. World J. Surg. 2013; 37 (2): 452-458. PMID: 23188527. doi: 10.1007/s00268-012-1840-5.

3. van Lienden K.P., van den Esschert J.W., de Graaf W., Bipat S., Lameris J.S., van Gulik T.M., van Delden O.M. Portal vein embolization before liver resection: a systematic review. Cardiovasc. Interv. Radiol. 2013; 36 (1): 25-34. PMID: 22806245. doi: 10.1007/s00270-012-0440-y.

4. Leung U., Simpson A.L., Araujo R.L., Gönen M., McAuliffe C., Miga M.I., Parada E.P., Allen P.J., D'Angelica M.I., Kingham T.P., DeMatteo R.P., Fong Y., Jarnagin W.R. Remnant growth rate after portal vein embolization is a good early predictor of post-hepatectomy liver failure. J. Am. Coll. Surg. 2014; 219 (4): 620-630. PMID: 25158914.

doi: 10.1016/j.jamcollsurg.2014.04.022.

5. Lim C., Mise Y., Sakamoto Y., Yamamoto S., Shindoh J., Ishizawa T., Aoki T., Hasegawa K., Sugawara Y., Makuuchi M., Kokudo N. Above $5 \mathrm{~cm}$ size does not matter anymore in patients with hepatocellular carcinoma. World J. Surg. 2014; 38 (11): 2910-2918. PMID: 25099682. doi: 10.1007/s00268-014-2704.

6. Clavien P.A., Petrowsky H., De Oliveira M.L., Graf R. Strategies for safer liver surgery and partial liver transplantation. N. Engl. J. Med. 2007; 356 (15): 1545-1559. PMID: 17429086. doi: 10.1056/NEJMra065156.

7. Azoulay D., Castaing D., Krissat J., Smail A., Hargreaves G.M., Lemoine A., Emile J.F., Bismuth H. Percutaneous portal vein embolization increases the feasibility and safety of major liver resection for hepatocellular carcinoma in injured liver. Ann. Surg. 2000; 232 (5): 665-672. PMID: 11066138.

8. Abdalla E.K., Barnett C.C., Doherty D., Curley S.A., Vauthey J.N. Extended hepatectomy in patients with hepatobiliary malignancies with and without preoperative portal vein 
embolization. Arch. Surg. 2002; 137 (6): 675-680; discussion 680-681. PMID: 12049538.

9. Abulkhir A., Limongelli P., Healey A.J., Damrah O., Tait P., Jackson J., Habib N., Jiao L.R. Preoperative portal vein embolization for major liver resection: a meta-analysis. Preoperative portal vein embolization for major liver resection: a meta-analysis. Ann. Surg. 2008; 247 (1): 49-57. PMID: 18156923. doi: 10.1097/SLA.0b013e31815f6e5b.

10. Vauthey J.N., Chaoui A., Do K.A., Bilimoria M.M., Fenstermacher M.J., Charnsangavej C., Hicks M., Alsfasser G., Lauwers G., Hawkins I.F., Caridi J. Standardized measurement of the future liver remnant prior to extended liver resection: methodology and clinical associations. Surgery. 2000; 127 (5): 512-519. PMID: 10819059. doi: 10.1067/msy.2000.105294.

11. Morise Z., Kawabe N., Tomishige H., Nagata H., Kawase J., Arakawa S., Yoshida R., Isetani M. Recent advances in liver resection for hepatocellular carcinoma. Front. Surg. 2014; 16 (1): 21. PMID: 25593945. doi: 10.3389/fsurg.2014.00021.

12. Shindoh J., Tzeng C.W., Aloia T.A., Curley S.A., Huang S.Y., Mahvash A., Gupta S., Wallace M.J., Vauthey J.N. Safety and efficacy of portal vein embolization before planned major or extended hepatectomy: an institutional experience of 358 patients. J. Gastrointest. Surg. 2014; 18 (1): 45-51. PMID: 24129824. doi: 10.1007/s11605-013-2369-0.

13. Choi J.H., Hwang S., Lee Y.J., Kim K.H., Ko G.Y., Gwon D.I., Ahn C.S., Moon D.B., Ha T.Y., Song G.W., Jung D.H., Lee S.G. Prognostic effect of preoperative sequential transcatheter arterial chemoembolization and portal vein embolization for right hepatectomy in patients with solitary hepatocellular carcinoma. Korean J. Hepatobiliary Pancreat. Surg. 2015; 19 (2): 59-65. PMID: 26155278. doi: 10.14701/kjhbps.2015.19.2.59.

14. Malinowski M., Geisel D., Stary V., Denecke T., Seehofer D., Jara M., Baron A., Pratschke J., Gebauer B., Stockmann M. Portal vein embolization with plug/coils improves hepatectomy outcome. J. Surg. Res. 2015; 194 (1): 202-211. PMID: 25454977. doi: 10.1016/j.jss.2014.10.028.

15. Pang T.C., Lam V.W. Surgical management of hepatocellular carcinoma. World J. Hepatol. 2015; 7 (2): 245-252. PMID: 25729479. doi: 10.4254/wjh.v7.i2.245.

16. Kwon A.H., Matsui Y., Ha-Kawa S.K., Kamiyama Y. Functional hepatic volume measured by technetium-99m-galactosylhuman serum albumin liver scintigraphy: comparison between hepatocyte volume and liver volume by computed tomography. Am. J. Gastroenterol. 2001; 96 (2): 541-546. PMID: 11232703. doi: 10.1111/j.1572-0241.2001.03556.x.

17. Bennink R.J., Dinant S., Erdogan D., Heijnen B.H., Straatsburg I.H., van Vliet A.K., van Gulik T.M. Preoperative assessment of postoperative remnant liver function using hepatobiliary scintigraphy. J. Nucl. Med. 2004; 45 (6): 965-971. PMID: 15181131.

18. de Graaf W., van Lienden K.P., Dinant S., Roelofs J., Busch O., Gouma D.G., Bennink R.J., van Gulik T.M. Assessment of future remnant liver function using hepatobiliary scintigraphy in patients undergoing major liver resection. J. Gastrointest. Surg. 2010; 14 (2): 369-378. PMID: 19937195. doi: 10.1007/s11605-009-1085-2.

19. Balzan S., Belghiti J., Farges O., Ogata S., Sauvanet A., Delefosse D., Durand F. The "50-50 criteria" on postoperative day 5: an accurate predictor of liver failure and death after hepatectomy. Ann. Surg. 2005; 242 (6): 824-828. PMID: 16327492.

20. Rahbari N.N., Garden O.J., Padbury R., Brooke-Smith M., Crawford M., Adam R., Koch M., Makuuchi M., Dematteo R.P.,
Christophi C., Banting S., Usatoff V., Nagino M., Maddern G., Hugh T.J., Vauthey J.-N., Greig P., Rees M., Yokoyama Y., Fan S.T., Nimura Y., Figueras J., Capussotti L., Büchler M.W., Weitz J. Posthepatectomy liver failure: a definition and grading by the International Study Group of Liver Surgery (ISGLS). Surgery. 2011; 149 (5): 713-724.

doi: http://dx.doi.org/10.1016/j.surg.2010.10.001.

21. Oellerich M., Burdelski M., Lautz H.U., Binder L., Pichlmayr R. Predictors of one-year pretransplant survival in patients with cirrhosis. Hepatology. 1991; 14 (6): 1029-1034. PMID: 1959850.

22. Faybik P., Hetz H. Plasma disappearance rate of indocyanine green in liver dysfunction. Transplant. Proc. 2006; 38 (3): 801802. PMID: 16647475. doi: 10.1016/j.transproceed.2006.01.049.

23. Mukherjee S., Rogers M.A., Buniak B. Comparison of indocyanine green clearance with Child's-Pugh score and hepatic histology: a multivariate analysis. Hepatogastroeneterology. 2006; 53 (67): 120-123. PMID: 16506389.

24. Schindl M.J., Redhead D.N., Fearon K.C., Garden O.J., Wigmore S.J. Edinburgh Liver Surgery and Transplantation Experimental Research Group (eLISTER). The value of residual liver volume as a predictor of hepatic dysfunction and infection after major liver resection. Gut. 2005; 54 (2): 289-296. PMID: 15647196. doi: 10.1136/gut.2004.046524.

25. Hshieh T.T., Sundaram V. Liver transplantation for hepatocellular carcinoma: are international guidelines possible? Hepatobiliary Surg. Nutr. 2013; 2 (2): 113-116. PMID: 24570925. doi: 10.3978/j.issn.2304-3881.2012.10.03.

26. van den Esschert J.W., de Graaf W., van Lienden K.P., Busch O.R., Heger M., van Delden O.M., Gouma D.J., Bennink R.J., Laméris J.S., van Gulik T.M. Volumetric and functional recovery of the remnant liver after major liver resection with prior portal vein embolization. J. Gastrointest. Surg. 2009; 13 (8): 1464-1469. PMID: 19475462. doi: 10.1007/s11605-009-0929-0.

27. Shoup M., Gonen M., D'Angelica M., Jarnagin W.R., DeMatteo R.P., Schwartz L.H., Tuorto S., Blumgart L.H., Fong Y. Volumetric analysis predicts hepatic dysfunction in patients undergoing major liver resection. J. Gastrointest. Surg. 2003; 7 (3): 325-330. PMID: 12654556.

28. Clavien P.A., Emond J., Vauthey J.N., Belghiti J., Chari R.S., Strasberg S.M. Protection of the liver during hepatic surgery. J. Gastrointest. Surg. 2004; 8 (3): 313-327. PMID: 15019929. doi: 10.1016/j.gassur.2003.12.006.

29. Denson K.W., Reed S.V., Haddon M.E. Validity of the INR system for patients with liver impairment. Thromb. Haemost. 1995; 73 (1): 162. PMID: 7740488.

30. Robert A., Chazouilleres O. Prothrombin time in liver failure: time, ratio, activity percentage, or international normalized ratio? Hepatology. 1996; 24 (6): 1392-1394. PMID: 8938167. doi: 10.1053/jhep.1996.v24.pm0008938167.

31. Angermayr B., Cejna M., Karnel F., Gschwantler M., Koenig F., Pidlich J., Mendel H., Pichler L., Wichlas M., Kreil A., Schmid M., Ferlitsch A., Lipinski E., Brunner H., Lammer J., Ferenci P., Gangl A., Peck-Radosavljevic M. Child-Pugh versus MELD score in predicting survival in patients undergoing transjugular intrahepatic portosystemic shunt. Gut. 2003; 52 (6): 879-885. PMID: 12740346.

32. Jeong E.M., Hwang S.G., Park H.H., Park J.H., Kim H.T., Oh S.W., Kho K.H., Hong S.P., Park P.W., Rim G.S., Kim S.H. The anaylsis of mortality rate according to CTP score and MELD score in patients with liver cirrhosis. Taehan. Kan. Hakhoe. Chi. 2003; 9 (2): 98-106. PMID: 12824749. 
33. Papatheodoridis G.V., Cholongitas E., Dimitriadou E., Touloumi G., Sevastianos V., Archimandritis A.J. MELD vs Child-Pugh and creatinine-modified Child-Pugh score for predicting survival in patients with decompensated cirrhosis. World J. Gastroenterol. 2005; 11 (20): 3099-3104. PMID: 15918197.

34. Yoon C.J., Chung J.W., Park J.H. Transjugular intrahepatic portosystemic shunt for acute variceal bleeding in patients with viral liver cirrhosis: predictors of early mortality. Am. J. Roentgenol. 2005; 185 (4): 885-889. PMID: 16177405. doi: 10.2214/AJR.04.0607.

35. Saab S., Landaverde C., Ibrahim A.B., Durazo F., Han S., Yersiz H., Farmer D.G., Ghobrial R.M., Goldstein L.I., Tong M.J., Busuttil R.W. The MELD score in advanced liver disease: association with clinical portal hypertension and mortality. Exp. Clin. Transplant. 2006; 4 (1): 395-399. PMID: 16827633.

36. Forman L.M., Lucey M.R. Predicting the prognosis of chronic liver disease: an evolution from Child to MELD. Hepatology. 2001; 33 (2): 473-475. PMID: 11172352. doi: $10.1053 /$ jhep. 2001.22481 .

37. Reuben A. Child comes of age. Hepatology. 2002; 35 (1): 244-245. PMID: 11786987. doi: 10.1053/jhep.2002.0350244.

38. Chalasani N., Clark W.S., Martin L.G., Kamean J., Khan M.A., Patel N.H., Boyer T.D. Determinants of mortality in patients with advanced cirrhosis after transjugular intrahepatic portosystemic shunting. Gastroenterology. 2000; 118 (1): 138-144. PMID: 10611162.

39. Dutkowski P., Oberkofler C.E., Béchir M., Müllhaupt B., Geier A., Raptis D.A., Clavien P.A. The model for end-stage liver disease allocation system for liver transplantation saves lives, but increases morbidity and cost: a prospective outcome analysis. Liver Transpl. 2011; 17 (6): 674-684. PMID: 21618688. doi: $10.1002 / 1 \mathrm{t} .22228$.

40. Abradelo M., Jiménez C. Splitting liver grafts for two adults: suboptimal grafts or suboptimal matching? Hepatobiliary Surg. Nutr. 2013; 2 (5): 242-243. PMID: 24570952. doi: 10.3978/j.issn.2304-3881.2013.08.05.

41. Kobayashi T., Kubota K., Imamura H., Hasegawa K., Inoue Y., Takayama T., Makuuchi M. Hepatic phenylalanine metabolism measured by the [13C]phenylalanine breath test. Eur. J. Clin. Invest. 2001; 31 (4): 356-361. PMID: 11298784.

42. Redaelli C.A., Dufour J.F., Wagner M., Schilling M., Hiisler J., Ki-ahenbuhl L., Buckler M.W., Reichen J. Preoperative galactose elimination capacity predicts complications and survival after hepatic resection. Ann. Surg. 2002; 235 (1): 77-85. PMID: 11753045.

43. Li Y.M., Lu F., Xu X., Ji H., Gao W.T., Lei T.J., Ren G.B., Bai Z.L., Li Q. Evaluation of liver functional reserve by combining D-sorbitol clearance rate and CT measured liver volume. World J. Gastroenterol. 2003; 9 (9): 2092-2095. PMID: 12970913.

44. Giannini E.G., Fasoli A., Borro P., Botta F., Malfatti F., Fumagalli A., Testa E., Polegato S., Cotellessa T., Milazzo S., Risso D., Testa R. 13C-galactose breath test and 13C-aminopyrine breath test for the study of liver function in chronic liver disease. Clin. Gastroenterol. Hepatol. 2005; 3 (3): 279-285. PMID: 15765448.

45. Tarantino G. Could quantitative liver function tests gain wide acceptance among hepatologists? World J. Gastroenterol. 2009; 15 (28): 3457-3461. PMID: 19630098.

46. Jepsen P., Vilstrup H., Ott P., Keiding S., Andersen P.K., Tygstrup N. The galactose elimination capacity and mortality in 781 Danish patients with newly-diagnosed liver cirrhosis: a cohort study. BMC Gastroenterol. 2009; 9: 50. PMID: 19566919. doi: 10.1186/1471-230X-9-50.

47. Schneider P.D. Preoperative assessment of liver function. Surg. Clin. North Am. 2004; 84 (2): 355-373. PMID: 15062650. doi: 10.1016/S0039-6109(03)00224-X.

48. Imamura H., Sano K., Sugawara Y., Kokudo N., Makuuchi M. Assessment of hepatic reserve for indication of hepatic resection: decision tree incorporating indocyanine green test. J. Hepatobiliary Pancreat. Surg. 2005; 12 (1): 16-22. PMID: 15754094. doi: 10.1007/s00534-004-0965-9.

49. de Graaf W., Häusler S., Heger M., van Ginhoven T.M., van Cappellen G., Bennink R.J., Kullak-Ublick G.A., Hesselmann R., van Gulik T.M., Stieger B. Transporters involved in the hepatic uptake of $(99 \mathrm{~m}) \mathrm{Tc}-$ mebrofenin and indocyanine green. J. Hepatol. 2011; 54 (4): 738-745. PMID: 21163547. doi: 10.1016/j.jhep.2010.07.047.

50. Das B.C., Isaji S., Kawarada Y. Analysis of 100 consecutive hepatectomies: risk factors in patients with liver cirrhosis or obstructive jaundice. World J. Surg. 2001; 25 (3): 266-273. PMID: 11343174. doi: 10.1007/s002680020059.

51. Lau H., Man K., Fan S.T., Yu W.C., Lo C.M., Wong J. Evaluation of preoperative hepatic function in patients with hepatocellular carcinoma undergoing hepatectomy. Br. J. Surg. 1997; 84 (9): 1255-1259. PMID: 9313707. 